\title{
Preharvest Chitosan and Postharvest UV Irradiation Treatments Suppress Gray Mold of Table Grapes
}

G. Romanazzi, Department of Environmental and Crop Sciences, Marche Polytechnic University, 60131 Ancona, Italy; F. Mlikota Gabler, Institute for Adriatic Crops, 21000 Split, Croatia; and J. L. Smilanick, United States Department of Agriculture-Agricultural Research Service, Horticultural Crops Research Laboratory, San Joaquin Valley Agricultural Sciences Center, Parlier, CA 93648

\begin{abstract}
Romanazzi, G., Mlikota Gabler, F., and Smilanick, J. L. 2006. Preharvest chitosan and postharvest UV irradiation treatments suppress gray mold of table grapes. Plant Dis. 90:445-450.

The effectiveness of chitosan treatment of table grapes, alone or in combination with ultraviolet$\mathrm{C}$ (UV-C) radiation, to control postharvest gray mold caused by Botrytis cinerea, was determined in California, United States. The influence of these treatments on catechin and resveratrol contents and chitinase activity in grape berry skins also was assessed. Clusters of cvs. Thompson Seedless, Autumn Black, and Emperor were sprayed in the vineyard with $1 \%$ chitosan, then harvested daily for 5 days. Promptly after harvest, they were inoculated with $B$. cinerea. Decay incidence and disease severity were significantly reduced by chitosan, which was most effective on berries harvested 1 or 2 days after treatment. In another experiment, grape berries were sprayed in the vineyard with chitosan, harvested 2 days later, irradiated for 5 min with UV-C $\left(0.36 \mathrm{~J} / \mathrm{cm}^{2}\right)$, and inoculated with $B$. cinerea 2 days later. Combined chitosan and UV-C treatments applied to cv. Autumn Black or selection B36-55 were synergistic in reducing gray mold incidence and severity compared with either treatment alone. Preharvest chitosan treatment increased neither concentration of catechin or resveratrol nor activity of chitinase in berry skin. Conversely, UV-C irradiation, alone or combined with chitosan treatment, induced catechin in cv. Autumn Black berries and trans-resveratrol in both cv. Autumn Black and selection B36-55.
\end{abstract}

Additional keywords: blue mold, Penicillium sp., Vitis vinifera

Gray mold, caused by Botrytis cinerea Pers., is the most economically important postharvest disease of table grapes (10). It is responsible for significant losses of table grape berries both before and after harvest, and is a major obstacle to long-distance transport and storage. Control of the disease is especially important in storage because it develops at cold temperatures $\left(-0.5^{\circ} \mathrm{C}\right)$ and spreads quickly among berries. Currently in California, gray mold in storage is controlled primarily by sulfur dioxide fumigation (28). However, there is a growing consumer demand for food without chemical preservatives, and its residues can be harmful for people allergic to sulfites. Concerns about residues in grape berries and other foods caused sulfur dioxide to be removed in 1986 from the United States Food and Drug Administration Generally Recognized as Safe (GRAS) compound list $(3,50)$; that shift encouraged research on alternative approaches. Sulfur dioxide applications also

Corresponding author: G. Romanazzi

E-mail: g.romanazzi@univpm.it

Accepted for publication 4 November 2005.

DOI: 10.1094/PD-90-0445

(C) 2006 The American Phytopathological Society can cause phytotoxicity symptoms, including bleaching of the berries and browning of the rachis $(35,48)$.

Chitosan, an $\mathrm{N}$-acetylated derivative of the polysaccharide chitin, is a natural polymer with a polycationic nature which has numerous applications in agriculture and agroindustries (34). Chitosan is an ideal preservative coating for fresh fruit and vegetables because it has a diseasesuppressive effect resulting from both physical and biochemical mechanisms (33). The physical properties of the polymer allow it to produce a film on the surface of treated fruit $(16,33)$. Chitosan also inhibits the growth of decay-causing fungi $(2,18,40)$ and induces defense responses in several plant systems, mostly in dicotyledon plants (47). It elicited phytoalexin biosynthesis in pea (23) and induced the production of antifungal hydrolases in groundnut and orange $(4,46)$. The elicitor activity of chitosan seems to arise from the interaction of its polycationic molecule with negatively charged phospholipids of host cell membranes (25). Chitosan treatment prolongs storage life and controls decay of cucumber, carrot, apple, citrus, kiwifruit, peach, pear, strawberry, and sweet cherry $(4,6,15,18,19,27,32,37,39,40,53)$. A commercial formulation based on chitosan (Elexa-4; Glycogenesys Inc., Boston) is available and registered in the United
States (Environmental Protection Agency no. 70464-3) for the control of gray mold and powdery mildew of grapes.

UV-C (ultraviolet-C) irradiation, with a wavelength of $254 \mathrm{~nm}$, is another method to control postharvest decay of fruit and vegetables. Prestorage treatment of pome fruit, stone fruit, citrus fruit, tomato, mango, and table grapes with low doses of UV-C was reported to reduce postharvest decay $(11,20,22,36,49)$. UV-C irradiation has been shown to induce defense responses in several fruit and vegetable species $(20,29,49)$.

Grape berries contain several substances with antifungal activity, such as tannins and phenolic compounds, that are reported to be important for resistance to gray mold (45). Other substances are not preformed, but are produced following infection by the pathogen. Defense reactions by grapevine to $B$. cinerea infection include synthesis of phytoalexins, mainly stilbenes, such as trans- and cis-resveratrol, catechin, $\alpha$ - and $\varepsilon$-viniferin, and pterostilbene $(1,12,26)$, and the synthesis of pathogenesis-related (PR) proteins, including chitinase, $\beta-1,3$ glucanase, phenylalanine ammonia-lyase (PAL), and stilbene synthase $(7,13)$. The property of the plant to produce these compounds and the rapidity of the response are related to the pathogen resistance of the host.

Chitosan induced PAL activity in treated berries (41). Nothing has been reported about the influence of chitosan treatment on the induction of catechin, resveratrol, or chitinase synthesis in grape berries; moreover, it is not known if chitosan-treated berries exposed to UV-C irradiation would exhibit an increase in catechin and resveratrol content.

The objectives of this study were to investigate (i) effectiveness of vineyard applications of chitosan to control postharvest gray mold and to induce catechin, resveratrol, and chitinase content in table grape berries, and (ii) possible better decay control and enhanced host resistance by irradiation of chitosan-treated berries with UV-C.

\section{MATERIALS AND METHODS}

Table grapes. Table grapes (Vitis vinife$r a$ L.) cvs. Thompson Seedless, Autumn Black, Emperor, and green grape selection B36-55 ( $V$. vinifera L., $V$. rupestris Scheele, and $V$. lincecumii Buchkl.) were 
grown according to standard cultural practices (28) in a United States Department of Agriculture-Agricultural Research Service (USDA-ARS) vineyard in Fresno, CA. No fungicides were applied prior to harvest. Mature clusters from several grapevines were used. Before the treatments, the soluble solids content of the berries was determined by refractometer using a sample of randomly selected berries. Only clusters with soluble solids content of $16 \%$ or higher were included in tests.

Chitosan. Crab-shell chitosan (SigmaAldrich, St Louis) was ground to a fine powder in a mortar, washed three times with distilled water, pelleted by low-speed centrifugation, and air dried at room temperature. Sheets of chitosan were solubilized by stirring in $0.25 \mathrm{~N} \mathrm{HCl}$, centrifuged to remove insoluble material, and precipitated by neutralization with $\mathrm{NaOH}$. The chitosan pellets were recovered by centrifugation, washed with deionized water to remove salts, and freeze dried (5). For experimental use, the solution $(1 \% \mathrm{wt} / \mathrm{vol})$ of chitosan was prepared by dissolving, under continuous stirring, the purified chitosan in $0.5 \%$ (vol/vol) acetic acid $(15,41)$. When dissolved, the $\mathrm{pH}$ of the chitosan solution was adjusted to 5.6 using $1 \mathrm{~N} \mathrm{NaOH}$, and $0.1 \%$ (wt/vol) of surfactant Triton X-100 was added to improve the wetting properties of the solution. All reagents were purchased from SigmaAldrich unless otherwise stated.

Preharvest chitosan treatments. The chitosan solution was sprayed on mature clusters on four vines of each cultivar using an engine sprayer delivering about 1,000 liters/ha until clusters were wet to runoff. Additional clusters were sprayed with deionized water at $\mathrm{pH} 5.6$ as controls. As soon as the clusters had dried, portions containing about 15 berries were harvested from each of 40 clusters. Harvesting was repeated at $1,2,3,4$, and 5 days after the chitosan application. Healthy berries were removed from the small cluster portions with the pedicel intact, pooled together, and randomized. These berries were used in subsequent experiments.

UV-C irradiation. A subset of berries harvested 2 days after chitosan treatment had an additional treatment imposed and were irradiated using two germicidal lowpressure mercury-vapor discharge lamps (General Electric, Fairfield, CT) emitting quasi-monochromatic UV radiation at 254 $\mathrm{nm}$ as described by El Ghaouth et al. (20). The berries were placed in plastic trays in a single layer approximately $10 \mathrm{~cm}$ from the surface of the lamp, and irradiated with $0.36 \mathrm{~J} / \mathrm{cm}^{2}$. After $5 \mathrm{~min}$ of irradiation, berries were rotated on their longitudinal axis to expose the other side of the berries to the same UV-C dose, and irradiated for an additional $5 \mathrm{~min}$. Irradiated berries and controls were incubated for $48 \mathrm{~h}$ at $20 \pm$ $1^{\circ} \mathrm{C}$ and 95 to $98 \%$ relative humidity (RH), then inoculated with $B$. cinerea.
Inoculum preparation. $B$. cinerea isolate 1440 from grapes (obtained from Themis Michailides, Kearney Agricultural Center, Parlier, CA) was stored at $-80^{\circ} \mathrm{C}$ on silica gel and cultured on potato dextrose agar (PDA) for 2 weeks at $23 \pm 1^{\circ} \mathrm{C}$ as needed. A spore suspension was created by flooding plates with a small volume of sterile distilled water plus surfactant (0.05\% Triton X-100), and spores were removed by gently scraping with a glass rod. The resulting spore suspension was filtered through four layers of cheesecloth and diluted with sterile water to an absorbance of 0.25 at $425 \mathrm{~nm}$ as determined by a spectrophotometer (Model 340; SequoiaTurner, Mountain View, CA). This density contained about $1.0 \times 10^{6}$ conidia/ml and was diluted with sterile water to obtain the desired spore concentrations. We used different inoculum concentrations in order to infect a minimum of $50 \%$ of the berries among control treatments of the cultivars: a concentration of $1 \times 10^{5}$ spores $/ \mathrm{ml}$ was used in inoculations of Thompson seedless, which is very susceptible to $B$. cinerea infection, and $5 \times 10^{5}$ spores $/ \mathrm{ml}$ for the moderately resistant Autumn Black, Emperor, and B36-55 cultivars (31). A volume of $50 \mathrm{ml}$ of inoculum was applied to about 500 berries with an air-brush sprayer (model 180-11; Badger Air-brush Co., Franklin Park, IL).

Inoculation with $B$. cinerea. To determine the susceptibility of chitosan-treated berries to subsequent infections by gray mold, berries were inoculated by spraying with the $B$. cinerea spore suspension until runoff. Berries were air dried for $30 \mathrm{~min}$ after application of the spore suspension. Three replicates of 50 single berries each were used for each of the treatments. Experiments were repeated three times, once each on cvs. Thompson Seedless, Autumn Black, and Emperor.

Berries that were sprayed in the vineyard with chitosan and, 2 days later, irradiated with UV-C were incubated for $48 \mathrm{~h}$ at $20 \pm 1^{\circ} \mathrm{C}$ and 95 to $98 \% \mathrm{RH}$, then inoculated as previously described with an airbrush sprayer using $B$. cinerea at $5 \times 10^{5}$ spores $/ \mathrm{ml}$. Three replicates of 50 single berries each were used. Additional treatments were included as controls in this experiment (chitosan only, UV-C irradiation only, and a water control). The experiment was repeated twice, once on $\mathrm{cv}$. Autumn Black and again on selection B36-55.

After treatment, all berries were arranged individually on wire racks to avoid contact among them, placed in covered plastic boxes that contained moist paper towels, and stored for 7 days at $20 \pm 1{ }^{\circ} \mathrm{C}$ and 95 to $98 \% \mathrm{RH}$. Three replicates of 50 single berries each were used for each treatment.

Decay assessment. After storage, the gray mold incidence was recorded. Disease severity also was assessed according to the following empirical scale: $0=$ healthy berry; $1=$ one lesion 2 to $3 \mathrm{~mm}$ in diameter (beginning of infection); 2 = one lesion $10 \mathrm{~mm}$ in diameter; $3=$ several lesions or $25 \%$ of the berry infected; $4=26$ to $50 \%$ of the berry surface infected, sporulation present; $5=$ more than $50 \%$ of the berry surface infected, sporulation present. Blue mold infections arising from natural Penicillium sp. inoculum present on grape berries were also recorded.

Berry skin chemical characterization. Resveratrol, piceid (resveratrol glucoside), and catechin content and chitinase activity were measured in the berry skin of cvs. Thompson Seedless, Autumn Black, and Emperor that were treated in the vineyard with chitosan on the same day (0) or 1,2 , 3,4 , or 5 days earlier. Similarly, resveratrol, piceid, catechin, and chitinase content was quantified in the berry skin of cv. Autumn Black and selection B36-55 treated in the vineyard with chitosan, then harvested 2 days later and exposed to UV-C, after which they were incubated for an additional 2 days at $20 \pm 1^{\circ} \mathrm{C}$ and 95 to $98 \%$ RH. Skins from berries were peeled by hand in a nitrogen atmosphere to prevent oxidation of the extracted compounds. Each treatment included five replicates of 50 berries each. Berry skins were ground in liquid nitrogen using a porcelain mortar and pestle until pulverized and kept frozen at $-20^{\circ} \mathrm{C}$ until analyzed.

Catechin, cis- and trans-piceid, and cisand trans-resveratrol content was measured. Frozen berry skin powder $(5 \mathrm{~g})$ was added to $25 \mathrm{ml}$ of $100 \%$ ethanol, macerated in a high-speed homogenizer (UltraTurrax T-25; IKA Labortechnik, Staufen, Germany), and centrifuged at $8,000 \times g$ for $10 \mathrm{~min}$. The pellet was re-extracted twice with $25 \mathrm{ml}$ of ethanol each time. The three supernatants were pooled and reduced to about $5 \%$ of the original volume using a rotary evaporator (Buchi R-124 Rotavapor; Buchi Labortechnik AG, Flawil, Switzerland). The concentrated extract was diluted to $10 \mathrm{ml}$ in $100 \%$ ethanol, and kept at $-20^{\circ} \mathrm{C}$ until analyzed. Catechin and transresveratrol were obtained from SigmaAldrich, and trans-piceid was obtained from Polyphenols Laboratories (Sandnes, Norway). Cis isomers were prepared by UV irradiation of trans-resveratrol and trans-piceid for $1 \mathrm{~h}$. Compounds were identified by their retention times and UV spectra from 245 to $380 \mathrm{~nm}$. A highperformance liquid chromatography (series 1050; Hewlett Packard, Santa Clara, CA) with a 250-by-4.6-mm column (P/NO 0064097-EO, type Prodigy $5 \mu \mathrm{m}$ Octadecyl Silane (ODS) $100 \AA$; Phenomenex, Torrance, $\mathrm{CA}$ ) and a diode array UV-visible detector were used for analysis. Chromatography was performed at $30^{\circ} \mathrm{C}$ at a flow rate of $1.0 \mathrm{ml} / \mathrm{min}$. Detection wavelengths were 280 and $306 \mathrm{~nm}$. Berry skin extract was passed through a syringe membrane filter $(0.45 \mu \mathrm{m})$ and a volume of $25 \mu \mathrm{l}$ was 
injected. A linear gradient was delivered of a mobile phase containing $2 \%$ glacial acetic acid (solvent $\mathrm{A}$ ) and $80 \%$ acetonitrile plus $0.4 \%$ glacial acetic acid (solvent B) (31).

Chitinase (EC 3.2.1.14) activity was assessed according to the method of Byrne et al. (8), with some modifications. Berry skin powder $(4 \mathrm{~g})$ was added to $10 \mathrm{ml}$ of $50 \mathrm{mM}$ sodium acetate buffer at $\mathrm{pH} 5.0$ and macerated in a high-speed homogenizer (Ultra-Turrax T-25), and $1.8 \mathrm{ml}$ of the homogenate was centrifuged at 13,000 $\times g$ for $10 \mathrm{~min}$. The supernatant $(100 \mu \mathrm{l})$ was incubated for $1 \mathrm{~h}$ at $25 \pm 1^{\circ} \mathrm{C}$ in an Eppendorf microcentrifuge tube containing $200 \mu \mathrm{l}$ of CM-Chitin-RVB (Loewe Biochemica, Sauerlach, Germany) and $500 \mu \mathrm{l}$ of $50 \mathrm{mM}$ sodium acetate buffer at $\mathrm{pH} 5$. The reaction was stopped by adding $200 \mu \mathrm{l}$ of $2 \mathrm{M} \mathrm{HCl}$ and cooling the tube on ice for $10 \mathrm{~min}$. The suspension was centrifuged at $13,000 \times g$ for $5 \mathrm{~min}, 100 \mu \mathrm{l}$ of the supernatant was decanted into a 96-well plate, and absorbance was read at $550 \mathrm{~nm}$. The blank was the reaction with all ingredients and no incubation, stopped by addition of $\mathrm{HCl}$ soon after their mixture.

Statistical analysis. Homogeneity of variance was tested using Levene's test (SPSS Inc., Chicago). To normalize the data, appropriate transformations were determined empirically using normal probability plots. Arcsin of the square root of the proportion was applied to the decay incidence data. Values were submitted to analysis of variance and the means were separated by Fisher's Protected least significant difference test (SuperANOVA; Abacus Concepts, Inc., Berkeley, CA). Actual values are shown. To determine whether significant correlations existed among induced catechin, trans-resveratrol, and gray mold incidence and severity, Pearson's correlation coefficient was calculated using bivariate analysis (SPSS Inc.).

Limpel's formula, as described by Richer (38), was applied to determine synergistic interactions between chitosan and UVC treatments. Limpel's formula is $E_{\mathrm{e}}=X+$ $Y-(X Y / 100)$, in which $E_{\mathrm{e}}$ is the expected effect from additive responses of two treatments and $X$ and $Y$ are the percentages of decay reduction obtained when each agent was used alone. Thus, synergism exists if the combination of the two agents produces a value of decay reduction greater than $E_{\mathrm{e}}$.

\section{RESULTS}

Preharvest chitosan application significantly reduced gray mold incidence and severity on cvs. Thompson Seedless, Autumn Black, and Emperor. However, the effect decreased as time after chitosan application increased (Fig. 1). The reduction of gray mold incidence and severity in the test with Thompson Seedless grapes was significantly higher when berries were inoculated within 2 days after chitosan treatments. The magnitude of severity reductions for Thompson Seedless was higher than for Autumn Black and Emperor.

Preharvest chitosan applications in combination with UV-C treatments reduced gray mold incidence compared with the control (Fig. 2). Gray mold incidence was reduced 83.5 and $87.9 \%$ compared with the control in cv. Autumn Black and selection B36-55, respectively (Fig. 2). Gray mold severity, however, was signifi-

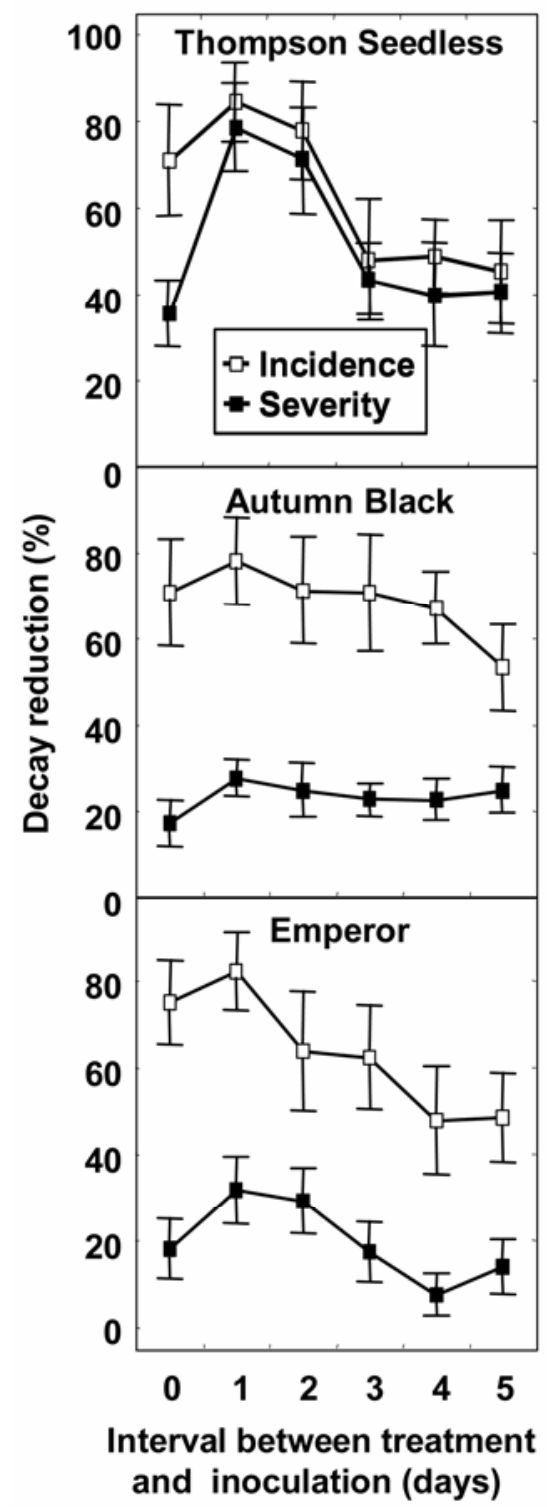

Fig. 1. Percent reduction in the incidence and severity ( \pm standard deviation) of gray mold on berries of table grapes cvs. Thompson Seedless, Autumn Black, and Emperor sprayed in the vineyard with $1 \%$ chitosan and harvested on the same day or $1,2,3,4$, or 5 days later, then inoculated with Botrytis cinerea $\left(1 \times 10^{5}\right.$ conidia/ml for Thompson Seedless or $5 \times 10^{5}$ conidia/ml for Autumn Black and Emperor). Berries were incubated 7 days at $20 \pm 1^{\circ} \mathrm{C}$ and 95 to $98 \%$ relative humidity. The incidence and severity of decay among control grape berries of all cultivars ranged from 58 to $76 \%$ and 2.9 to 4.6 , respectively. cantly reduced in both cultivars only by combining chitosan and UV-C (Fig. 3). All treatments also significantly reduced blue mold incidence compared with the control; the largest reduction, $89.5 \%$, occurred when combined chitosan and UV-C treatments were applied (Fig. 4). The combination of preharvest chitosan spraying and postharvest UV-C irradiation resulted in a greater reduction of gray mold incidence, gray mold severity, and blue mold incidence than the expected additive response $\left(E_{\mathrm{e}}\right)$, as determined by calculating the $E_{\mathrm{e}}$ values according to Limpel's formula (Figs. 2, 3, and 4). Thus, the combination of preharvest chitosan treatment and postharvest UV-C irradiation resulted in a synergistic effect in the control of gray mold and blue mold.

Catechin, cis-piceid, trans-piceid, cisresveratrol, trans-resveratrol, or chitinase activity were not detected in cvs. Thompson Seedless, Autumn Black, or Emperor berry skins, either in controls or in those treated only with chitosan.

In the experiments where chitosan was applied to clusters before harvest and berries later were exposed to UV-C irradiation, catechin was detected in berry skins
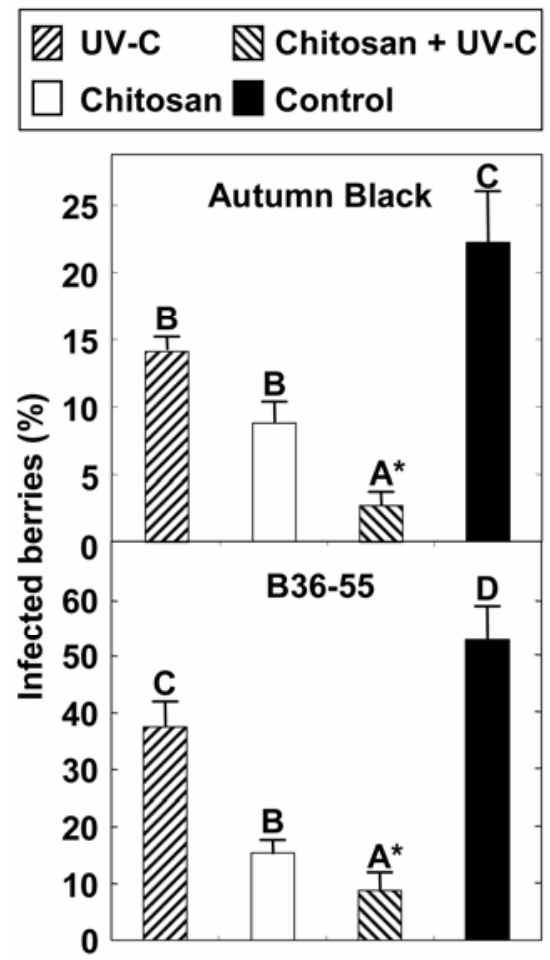

Fig. 2. Gray mold incidence $( \pm$ standard deviation) on berries of table grapes cv. Autumn Black and selection B36-55 sprayed in the vineyard with $1 \%$ chitosan, harvested $48 \mathrm{~h}$ later, irradiated with ultraviolet-C (UV-C), inoculated $48 \mathrm{~h}$ later with Botrytis cinerea at $5 \times 10^{5} \mathrm{co}^{-}$ nidia/ml, then incubated for 7 days at $20 \pm 1^{\circ} \mathrm{C}$ and 95 to $98 \%$ relative humidity. Values marked with the same letter are not statistically different according to Fisher's Protected least significant difference test, $P=0.01$. Asterisk (*) indicates synergistic effect according to the Limpel's formula. 
of cv. Autumn Black exposed to UV-C alone and in those treated with chitosan and later with UV-C. Berries treated with both chitosan and UV-C had significantly higher catechin content than those only irradiated with UV-C (Table 1). In cv. Autumn Black and selection B36-55, transresveratrol was detected both in berries exposed to UV-C alone and in berries treated with chitosan and later with UV-C. The berries treated with the combination of chitosan and UV-C had a significantly higher trans-resveratrol content than those only irradiated with UV-C (Table 1). Cisresveratrol, trans-piceid, cis-piceid, and chitinase activity were not detected in any of the samples.

In cv. Autumn Black, trans-resveratrol and catechin content was negatively correlated with decay incidence (Pearson correlation $=-0.82, P=0.001$ for both) and disease severity (Pearson correlation = $-0.72, P=0.009$ and Pearson correlation $=$ $-0.76, P=0.004$, respectively). In Autumn Black, a positive correlation was found
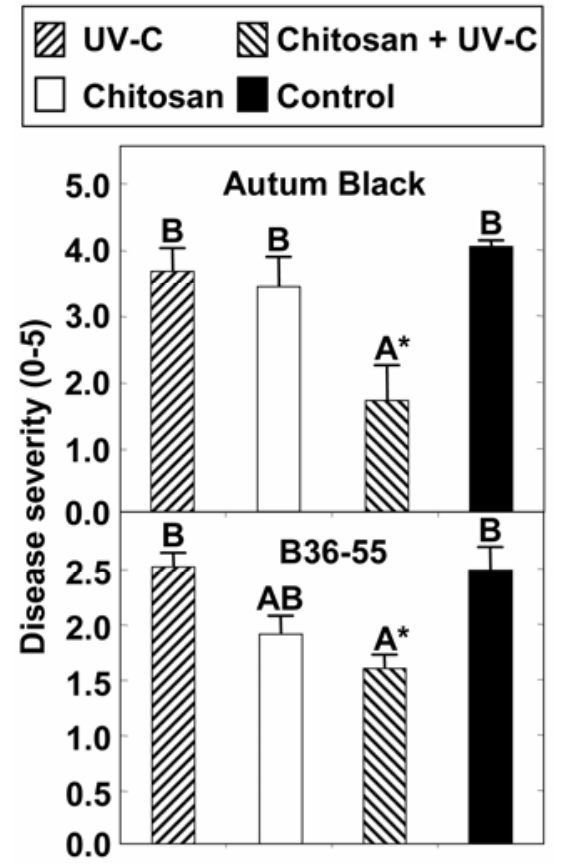

Fig. 3. Gray mold severity ( \pm standard deviation) on berries of table grapes cv. Autumn Black and selection B36-55 sprayed in the vineyard with $1 \%$ chitosan, harvested $48 \mathrm{~h}$ later, irradiated with ultraviolet-C (UV-C), inoculated $48 \mathrm{~h}$ later with Botrytis cinerea at 5 $\times 10^{5}$ conidia/ml, then incubated for 7 days at $20 \pm 1^{\circ} \mathrm{C}$ and 95 to $98 \%$ relative humidity. Severity was assessed according to a scale where $0=$ healthy berry; $1=$ one lesion 2 to 3 $\mathrm{mm}$ in diameter (beginning of infection); $2=$ one lesion $10 \mathrm{~mm}$ in diameter; $3=$ several lesions or $25 \%$ of the berry infected; $4=26$ to $50 \%$ of the berry surface infected, sporulation present; and $5=$ more than $50 \%$ of the berry surface infected, sporulation present. Values marked with the same letter are not statistically different according to Fisher's Protected least significant difference test, $P=0.01$. Asterisk $(*)$ indicates synergistic effect according to the Limpel's formula. between trans-resveratrol and catechin contents in the berry skin (Pearson correlation $=0.88, P=0.001)$. In selection B3655, trans-resveratrol content was negatively correlated with gray mold incidence (Pearson correlation $=-0.93, P=0.001$ ), gray mold severity (Pearson correlation = $-0.83, P=0.001)$, and blue mold incidence (Pearson correlation $=-0.75, P=0.005)$.

\section{DISCUSSION}

Preharvest chitosan treatment was effective in reducing gray mold infection on artificially inoculated berries during storage. When applied in the field, the polymer proved to be effective in controlling postharvest diseases of strawberry, sweet cherry, and table grapes $(37,39,43)$.

Preharvest applications of chitosan effectively controlled gray mold in cvs. Thompson Seedless, Autumn Black, and Emperor. In previous investigations, Thompson Seedless was reported to be susceptible to gray mold, and Autumn Black and Emperor were reported to be
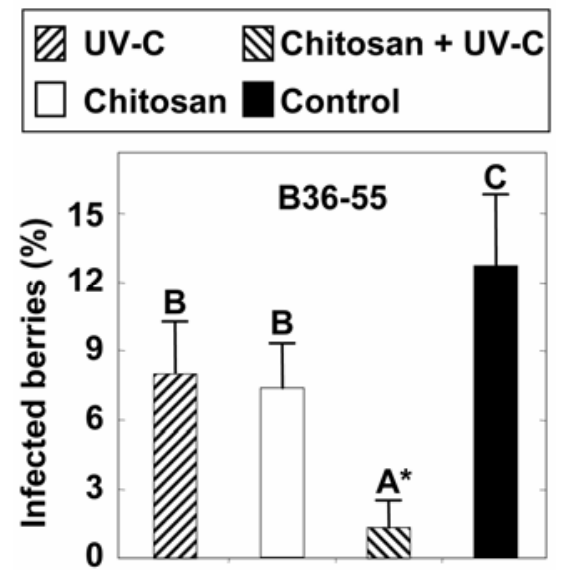

Fig. 4. Blue mold incidence ( \pm standard deviation) on berries of table grapes cv. Autumn Black and selection B36-55 arising from natural inoculations with Penicillium sp. Grape clusters were sprayed in the vineyard with $1 \%$ chitosan, harvested $48 \mathrm{~h}$ later, irradiated with ultraviolet-C (UV-C), then incubated for 7 days at $20 \pm 1^{\circ} \mathrm{C}$ and 95 to $98 \%$ relative humidity. Values marked with the same letter are not statistically different according to Fisher's Protected least significant difference test, $P=0.01$. Asterisk (*) indicates synergistic effect according to the Limpel's formula.

Table 1. Trans-resveratrol and catechin contents $(\mu \mathrm{g} / \mathrm{g})$ in berries of cv. Autumn Black and selection B36-55 preharvest treated with chitosan and postharvest exposed to ultraviolet-C (UV-C) irradiation ${ }^{\mathrm{y}}$

\begin{tabular}{lccccc}
\hline & \multicolumn{2}{c}{ Autumn Black $^{\mathbf{z}}$} & & \multicolumn{2}{c}{ B36-55 $^{\mathbf{z}}$} \\
\cline { 2 - 3 } \cline { 5 - 6 } Treatment & Trans-resveratrol & Catechin & & Trans-resveratrol & Catechin \\
\hline Chitosan & ND & ND & & $1.90 \mathrm{C}$ & ND \\
UV-C & $17.47 \mathrm{~b}$ & $1.41 \mathrm{~b}$ & & $18.12 \mathrm{~B}$ & ND \\
Chitosan + UV-C & $23.15 \mathrm{a}$ & $2.56 \mathrm{a}$ & & $22.00 \mathrm{~A}$ & ND \\
Control & ND & ND & & $1.84 \mathrm{C}$ & ND \\
\hline
\end{tabular}

${ }^{\mathrm{y}}$ Berry skins were peeled $48 \mathrm{~h}$ after irradiation under a nitrogen environment, extracted in ethanol, and analyzed by high-performance liquid chromatography. $\mathrm{ND}=$ not detected; limit of detection for each was $0.2 \mu \mathrm{g} / \mathrm{g}$.

${ }^{\mathrm{z}}$ Amount $(\mu \mathrm{g} / \mathrm{g}$ fresh weight) in grape berry skin $(n=5)$. Within each column, values followed by the same letter are not statistically different, according to Fisher's Protected least significant difference test; $P=0.01$ (capital letters) or $P=0.05$ (small letters). 
tosan and UV-C irradiation to control postharvest decay of fruit. Combined treatment of chitosan and UV-C irradiation is worthwhile, because it can exploit an additive or synergistic effect in decay reduction or elicitation of antifungal compounds (51). Chitosan and UV-C treatments had a synergistic interaction in reducing gray and blue mold of table grapes. To our knowledge, synergistic effects of the combination of chitosan and UV-C irradiation have not been reported previously. However, combinations of chitosan with sodium benzoate (44) or hypobaric treatments (42) had a synergistic interaction in their antimicrobial activity.

Berries treated with chitosan and exposed to UV-C had a higher catechin and trans-resveratrol induction compared with the same treatments applied alone. Fajardo et al. (21) reported that chitosan treatment alone did not induce chitinase activity in orange wounds; however, when oranges were treated with chitosan and later challenged with Penicillium digitatum Sacc., chitinase activity was elicited. Induced catechin in Autumn Black and induced trans-resveratrol in Autumn Black and B36-55 berry skins were negatively correlated with disease incidence and severity; therefore, they could be significant factors during plant-microbe interaction processes that contribute, among other features, to the suppression of disease development.

As control of postharvest diseases with a single alternative mean is not often as consistent as control with synthetic fungicides (51), the integrated strategy presented in this study, exploiting a synergistic effects of chitosan and UV-C treatments, could be a valid alternative. This possibility could be particularly suitable for certified organic growers, where sulfur dioxide cannot be used as a postharvest treatment of table grapes (30). UV-C irradiation could be applied in packinghouses by means of a bank of fluorescent lamps suspended above a conveyor where the table grape berries pass. Table grape berries often are packed in small, transparent plastic containers that would allow the penetration of $\mathrm{UV}-\mathrm{C}$ radiation. The height and number of the lamps and the conveyor belt speed must be optimized to determine the most effective exposure dosage. UV-C is a nonionizing irradiation and an extension of the visible spectrum; it is commercially used in water purification treatments (22). UV-C irradiation is of potential importance to control postharvest gray mold of table grapes and could be considered as a rapid, simple, and economical postharvest treatment. An online UV-C apparatus has been developed and its use effectively reduced gray and blue mold on apple during storage (52). However, the practical application of UV-C irradiation to control gray and blue mold of table grapes needs to be evaluated in large-scale tests.
The grape berries treated with chitosan and exposed to UV-C irradiation had a higher trans-resveratrol content than that of berries exposed to the single treatments alone, and trans-resveratrol is reported to be a beneficial compound because of its anticarcinogenic and antioxidant properties (24). However, further investigation is necessary to better understand the interaction between the two control agents, the effect of UV-C treatment on the film formed by chitosan on the berry surface, and the acceptability of chitosan-treated table grape berries by consumers.

\section{ACKNOWLEDGMENTS}

All experiments were conducted at the USDAARS, San Joaquin Valley Agricultural Sciences Center, Parlier, CA. A portion of the work was funded by Italian National Research Council (CNR) fellowship program (Bando n. 203.22).

\section{LITERATURE CITED}

1. Adrian, M., Jeandet, P., Douillet-Breuil, A. C., Tesson, L., and Bessis, R. 2000. Stilbene content of mature Vitis vinifera berries in response to UV-C elicitation. J. Agric. Food Chem. 48:6103-6105.

2. Allan, C. R., and Hadwiger, L. A. 1979. The fungicidal effect of chitosan on fungi of varying cell wall composition. Exp. Mycol. 3:285287.

3. Anon 1986. GRAS status of sulfiting agents for use on fresh and frozen foods revoked. Fed. Regist. 51:25021.

4. Benhamou, N. 2004. Potential of mycoparasite, Verticillium lecanii, to protect citrus fruit against Penicillium digitatum, the causal agent of green mold: a comparison with the effect of chitosan. Phytopathology 94:693-705.

5. Benhamou, N., Lafontaine, P. J., and Nicole, M. 1994. Induction of systemic resistance to Fusarium crown root rot in tomato plants by seed treatment with chitosan. Phytopathology 84:1432-1444.

6. Ben-Shalom, N., Ardi, R., Pinto, R., Aki, C., and Fallik, E. 2003. Controlling gray mould caused by Botrytis cinerea in cucumber plants by means of chitosan. Crop Prot. 22:285-290.

7. Bezier, A., Lambert, B., and Baillieul, F. 2002. Study of defense-related gene expression in grapevine leaves and berries infected with Botrytis cinerea. Eur. J. Plant Pathol. 108:111120.

8. Byrne, N. D., Duxbury, M., and Sharpe, N. 2001. The determination of chitinase activity of grapes: an introductory enzyme assay. Biochem. Mol. Biol. Educ. 29:144-146.

9. Cantos, E., Garcia-Viguera, C., de PascualTeresa, S., and Tomas-Barberan, F. A. 2000. Effect of postharvest irradiation on resveratrol and other phenolics of cv. Napoleon table grapes. J. Agric. Food Chem. 48:4606-4612.

10. Cappellini, R. A., Ceponis, M. J., and Lightner, G. W. 1986. Disorders in table grape shipments to the New York market, 1972-1984. Plant Dis. 70:1075-1079.

11. Chalutz, E., Droby, S., Wilson, C., and Wisniewski, M. 1992. UV-induced resistance to postharvest diseases of citrus fruit. J. Phytochem. Phytobiol. 15:367-374.

12. Creasy, L. L., and Coffee, M. 1988. Phytoalexin production potential of grape berries. J. Am. Soc. Hortic. Sci. 113:230-234.

13. Derckel, J.-P., Audran, J.-C., Haye, B., Lambert, B., and Legendre, L. 1998. Characterization, induction by wounding, and salicylic acid, and activity against Botrytis cinerea of chitinases and beta-1,3-glucanases of ripening grape berries. Physiol. Plant. 104:56-64.

14. Devlieghere, F., Vermeulen, A., and Debevere,
J. 2004. Chitosan: antimicrobial activity, interactions with food components, and applicability as a coating on fruit and vegetables. Food Microbiol. 21:703-714.

15. Du, J., Gemma, H., and Iwahori, S. 1997. Effects of chitosan coating on the storage of peach, Japanese pear and kiwifruit. J. Jpn. Soc. Hortic. Sci. 66:15-22.

16. Du, J., Gemma, H., and Iwahori, S. 1998 Effects of chitosan coating on the storability and on the ultrastructural changes of 'Jonagold' apple fruit in storage. Food Preserv. Sci. 24:23-29

17. Duxbury, M., Hotter, G., Reglinski, T., and Sharpe, N. 2004. Effect of chitosan and 3chlorosalicylic acid on total phenolic content of grapes and wine. Am. J. Enol. Vitic. 55:191194.

18. El Ghaouth, A., Arul, J., Grenier, J., and Asselin, A. 1992. Antifungal activity of chitosan on two postharvest pathogens of strawberry fruits. Phytopathology 82:398-402.

19. El Ghaouth, A., Smilanick, J. L., and Wilson, C. L. 2000. Enhancement of the performance of Candida saitoana by the addition of glycolchitosan for the control of postharvest decay of apple and citrus fruit. Postharvest Biol. Technol. 19:103-110.

20. El Ghaouth, A., Wilson, C. L., and Callahan, A. M. 2003. Induction of chitinase, $\beta-1,3$ glucanase, and phenylalanine ammonia-lyase in peach fruit by UV-C treatment. Phytopathology 93:349-355.

21. Fajardo, J. E., McCollum, T. G., McDonald, R. E., and Mayer, R. T. 1998. Differential induction of proteins in orange flavedo by biologically based elicitors and challenged by Penicillium digitatum Sacc. Biol. Control 13:143-151.

22. Gonzáles-Aguilar, G. A., Wang, C. Y., Buta, J. G., and Krizek, D. T. 2001. Use of UV-C irradiation to prevent decay and maintain postharvest quality of ripe "Tommy Atkins" mangoes. Int. J. Food Sci. Technol. 36:767-733.

23. Hadwiger, L. A., and Beckman, J. M. 1980. Chitosan as a component of pea-Fusarium solani interactions. Plant Physiol. 66:205-211.

24. Jang, M., Cai, L., Udeani, G. O., Slowing, K. V., Thomas, C. F., Beecher, C. W. W., Fong, H. H. S., Farnsworth, N. R., Kinghorn, A. D., Metha, R. G., Moon, R. C., and Pezzuto, J. M. 1997. Cancer chemopreventive activity of resveratrol, a natural product derived from grapes. Science 275:8-220.

25. Kauss, H., Jeblick, W., and Domard, A. 1989. The degree of polymerization and $\mathrm{N}$ acetylation of chitosan determine its ability to elicit callose formation in suspension cells and protoplasts of Catharanthus roseus. Planta 178:385-392.

26. Langcake, P., and McCarthy, W. V. 1979. The relationship of resveratrol production to infection of grapevine leaves by Botrytis cinerea. Vitis 18:244-253.

27. Li, H., and Yu, T. 2001. Effect of chitosan on incidence of brown rot, quality and physiological attributes of postharvest peach fruit. J. Sci. Food Agric. 81:269-274.

28. Luvisi, D., Shorey, H., Smilanick, J. L., Thompson, J., Gump, B. H., and Knutson, J. 1992. Sulfur dioxide fumigation of table grapes. Bulletin 1932, University of California, Division of Agriculture and Natural Resources, Oakland, CA.

29. Mercier, J., Arul, J., and Cohen, C. 1993. Effect of UV-C on phytoalexin accumulation and resistance to Botrytis cinerea in stored carrots. J. Phytopathol. 137:44-54.

30. Mlikota Gabler, F., and Smilanick, J. L. 2001 Postharvest control of table grape gray mold on detached berries with carbonate and bicarbonate salts and disinfectants. Am. J. Enol Vitic. 52:12-20

31. Mlikota Gabler, F., Smilanick, J. L., Mansour, M., Ramming, D. W., and Mackey, B. E. 2003 
Correlations of morphological, anatomical, and chemical features of grape berries with resistance to Botrytis cinerea. Phytopathology 93:1263-1273.

32. Molloy, C., Cheah, L. H., and Koolaard, J. P. 2004. Induced resistance against Sclerotinia sclerotiorum in carrots treated with enzymatically hydrolised chitosan. Postharvest Biol. Technol. 33:61-65.

33. Muzzarelli, R. A. A. 1986. Filmogenic properties of chitin/chitosan. Pages 389-396 in: Chitin in Nature and Technology. R. A. A. Muzzarelli, C. Jeuniaux, and G. W. Gooday, eds. Plenum Press, New York.

34. Muzzarelli C., and Muzzarelli, R. A. A. 2003. Chitin related food science today (and two centuries ago). Agrofood Ind. Hi-Tech 1:39-42.

35. Nelson, K. E., and Richardson, H. B. 1967. Storage temperature and sulfur dioxide treatment in relation to decay and bleaching of stored grapes. Phytopathology 57:950-955.

36. Nigro, F., Ippolito, A., and Lima, G. 1998. Use of UV-C light to reduce Botrytis storage rot of table grapes. Postharvest Biol. Technol. 13:171-181.

37. Reddy, B. M. V., Belkacemi, K., Corcuff, R., Castaigne, F., and Arul, J. 2000. Effect of preharvest chitosan sprays on post-harvest infection by Botrytis cinerea and quality of strawberry fruit. Postharvest Biol. Technol. 20:39-51.

38. Richer, D. L. 1987. Synergism: A patent view. Pesticide Sci. 19:309-315.

39. Romanazzi, G., Nigro, F., and Ippolito, A.
2000. Effectiveness of pre and postharvest chitosan treatments on storage decay of strawberries. Frutticoltura 62:71-75.

40. Romanazzi, G., Nigro, F., and Ippolito, A. 2001. Chitosan in the control of postharvest decay of some Mediterranean fruits. Pages 141-146 in: Chitin Enzymology. R. A. A. Muzzarelli, ed. Atec, Grottammare (AP), Italy.

41. Romanazzi, G., Nigro, F., Ippolito, A., Di Venere, D., and Salerno, M. 2002. Effects of pre and postharvest chitosan treatments to control storage grey mold of table grapes. J. Food Sci. 67:1862-1867.

42. Romanazzi, G., Nigro, F., and Ippolito, A. 2003. Short hypobaric treatments potentiate the effect of chitosan in reducing storage decay of sweet cherries. Postharvest Biol. Technol. 29:73-80.

43. Romanazzi, G., Schena L., Nigro F., and Ippolito A. 1999. Preharvest chitosan treatments for the control of postharvest decay of sweet cherries and table grapes. J. Plant Pathol. 81:237.

44. Sagoo, S. K., Board, R., and Roller, S. 2002. Chitosan potentiates the antimicrobial action of sodium benzoate on spoilage yeasts. Lett. Appl. Microbiol. 34:168-172.

45. Sarig, P., Zutkhi, Y., Lisker, N., Shkelerman, Y., and Ben-Arie, R. 1998. Natural and induced resistance of table grapes to bunch rots. Acta Hortic. 464:65-70.

46. Sathiyabama, M., and Balasubramanian, R. 1998. Chitosan induces resistance components in Arachis hypogaea against leaf rust caused by Puccinia arachidis Speg. Crop Prot. 17:307-313

47. Shibuya, N., and Minami, E. 2001. Oligosaccharide signalling for defence responses in plant. Physiol. Mol. Plant Pathol. 59:223-233.

48. Sholberg, P. L., Reynolds, A. G., and Gaunce, A. P. 1996. Fumigation of table grapes with acetic acid to prevent postharvest decay. Plant Dis. 80:1425-1428.

49. Stevens, C., Liu, J., Khan, V. A., Lu, J. Y., Kabwe, M. K., Wilson, C. L., Igwegbe, E. C. K., Chalutz, E., Droby, S. 2004. The effects of low-dose ultraviolet light-C treatment on polygalacturonase activity, delay ripening and Rhizopus soft rot development of tomatoes. Crop Prot. 23:551-554.

50. Taylor, S. L. 1993. Why sulfite alternatives. Food Technol. 47:14.

51. Wilson, C. L., El Ghaouth, A., Chalutz, E., Droby, S., Stevens, C., Lu, J. Y., Khan, V., and Arul, J. 1994. Potential of induced resistance to control postharvest diseases of fruits and vegetables. Plant Dis. 78:837-844.

52. Wilson, C. L., El Ghaouth, A., Upchurch, B., Stevens, C., Khan, V., Droby, S., and Chalutz E. 1997. Using an on-line UV-C apparatus to treat harvested fruit for controlling postharvest decay. HortTechnology 7:278-282.

53. Zhang, D., and Quantick, P. C. 1998. Antifungal effects of chitosan coating on fresh strawberries and raspberries during storage. J. Hortic. Sci. Biotech. 73:763-767. 